\title{
How does healthy aging impact on the circadian clock?
}

\author{
Aurel Popa-Wagner ${ }^{1} \cdot$ Ana-Maria Buga ${ }^{2} \cdot$ Dinu Iuliu Dumitrascu ${ }^{3} \cdot$ \\ Adriana Uzoni ${ }^{1} \cdot$ Johannes Thome $^{1} \cdot$ Andrew N. Coogan ${ }^{4}$
}

Received: 23 April 2015/Accepted: 30 June 2015/Published online: 15 July 2015

(C) Springer-Verlag Wien 2015

\begin{abstract}
Circadian rhythms are recurring patterns in a host of physiological and other parameters that recur with periods of near $24 \mathrm{~h}$. These rhythms reflect the temporal organization of an organism's homeostatic control systems and as such are key processes in ensuring optimal physiological performance. Dysfunction of circadian processes is linked with adverse health conditions. In this review we highlight the evidence that normal, healthy aging is associated with changes in the circadian system; we examine the molecular mechanisms through which such changes may arise, discuss whether more robust circadian function is a predictor of longevity and highlight the role of circadian rhythms in age-related diseases. Overall, the literature shows that aging is associated with marked changes in circadian processes, both at the behavioral and molecular levels, and the molecular mechanisms through which such changes arise remain to be elucidated, but may involve inflammatory process, redox homeostasis and epigenetic modifications. Understanding the nature of age-related circadian dysfunction will allow for the design of chronotherapeutic intervention strategies to attenuate
\end{abstract}

Aurel Popa-Wagner

aurel.popa-wagner@med.uni-rostock.de

1 Department of Psychiatry, University of Medicine Rostock, Gehlsheimerstr. 20, 18147 Rostock, Germany

2 Department of Functional Sciences, Center of Clinical and Experimental Medicine, University of Medicine and Pharmacy of Craiova, Craiova, Romania

3 Department of Anatomy and Embryology, UMF "Iuliu Hatieganu" Cluj, Cluj-Napoca, Romania

4 Maynooth University Department of Psychology, National University of Ireland, Maynooth, Co. Kildare, Ireland circadian dysfunction and thus improve health and quality of life.

Keywords Circadian · Aging · Clock gene · Inflammation · Longevity

\section{Introduction}

The world population is inexorably aging (Ferrucci et al. 2008). Among the many societal and health challenges that this situation poses is the need to understand how aging impacts on circadian rhythms and sleep, in order to delineate the impact that these changes may have on health and wellbeing. Circadian rhythms are recurring cycles in a host of physiological, biochemical and behavioral parameters that display periods of near $24 \mathrm{~h}$ (Dibner et al. 2010). Contribution to the timing of the sleep/wake cycle is one of the most prominent outputs of the circadian system and there is a complex interplay between the circadian and the homeostatic control systems in determining sleep onset and duration (Franken 2013).

Circadian rhythms are internally generated by an intrinsic circadian timekeeping system, which in turn interacts with rhythmic stimuli in the environment to produce biologically salient rhythms. Given the large number of mammalian processes that have been shown to be under some type of circadian control, it should be of no great surprise that clock dysfunction is linked with deleterious health outcomes (Smolensky et al. 2015). This point is further reinforced by consideration of the presence of molecular clocks in the vast majority of mammalian tissues and cell types, and the widespread influence of the clock on gene expression (Koike et al. 2012). In this review we discuss the evidence for circadian clock dysfunction in 
healthy aging, the impact of circadian timing for longevity and how circadian dysfunction may contribute to deleterious health outcomes in older age.

\section{Changes in circadian rhythms and sleep/wake behavior associated with aging}

Age has a marked effect on circadian rhythms and the temporal organization of sleep/wake behaviors. A striking example of this is alterations in the timing of sleep/wake behaviors (termed chronotype) and how these change over the developmental time course. Large-scale epidemiological studies indicate that chronotype, as indicated by the timing of the midpoint of sleep on non-work days, is profoundly influenced by age, with infancy and childhood being associated with early chronotype, adolescence with late chronotype and older age with early chronotype (Roenneberg et al. 2003). In terms of understanding the physiological basis for these gross patterns in daily behavior, analysis of older subjects under forced desynchrony protocols that allow for the accurate assessment of circadian rhythms, as opposed to sleep/wake rhythms, reveals that the period of circadian rhythms in older people does not differ from those in younger people (Czeisler et al. 1999). This finding indicates that the precision of the intrinsic circadian timing is not overtly impacted by healthy aging. However, numerous studies indicate that the amplitude of circadian rhythms is progressively blunted in healthy aging. This is manifested in a less clear demarcation between consolidated periods of waking and sleep, with more sleep episodes occurring in the day and more waking occurring during the night (reviewed in Hofman and Swaab 2006). Such disturbances may be of particular importance for many functional domains; for example, cognitive performance is predicted by circadian amplitude in older participants (Oosterman et al. 2009). There may also be altered phases of various rhythms in aging, with core body temperature and melatonin secretion showing altered phase (Duffy and Czeisler 2002; Yoon et al. 2003). These results may indicate that the circadian systems are less able to adjust to environmental time cues with age, and as a result are more prone to desynchronisation (ArellanesLicea et al. 2014).

\section{Anatomy and neurophysiology of the SCN pacemaker and aging}

Sleep is an active phenomenon that is controlled by various levels of the CNS (Stiller and Postolache 2005). The centers that are implicated in the homeostatic regulation of sleep state are located in the medulla oblongata, pons, locus coeruleus, substantia nigra, the basal forebrain and the hypothalamus (Stiller and Postolache 2005; Zeman and Reading 2005). Interestingly these nuclei are understood to be under the influence of the circadian system, and further feedback onto that system (Moore, 2007). The master circadian pacemaker of this system is located in the suprachiasmatic nucleus ( $\mathrm{SCN}$ ) of the anterior hypothalamus, which is a small bilateral structure located directly dorsal to the optic chiasm, through which it receives direct retinal innervations from intrinsically photosensitive retinal ganglion cells (Saper et al. 2005). The SCN then projects, mostly indirectly via other hypothalamic relay stations, extensively throughout the brain to control the phase of extra-SCN semi-autonomous local CNS clocks (Saper et al. 2005; Guilding and Piggins 2007). Phase information is also conveyed from the CNS to peripheral pacemakers through a complex mixture of autonomic, endocrine and other physiological signals (e.g. core body temperature) to ensure that that all of the constituent pacemakers of this system have appropriate phase-relationships; in other words, that there is internal synchrony (Dibner et al. 2010).

So an obvious place to start when trying to understand the nature of the mechanisms that give rise to alterations in sleep/wake behavior in normal aging is to ask whether there are anatomical and/or neurochemical variations that occur within the master SCN pacemaker. A number of studies have examined the SCN from post-mortem tissue and reported that there are not major gross pathological changes in the aged SCN; there is no evidence of marked cell loss in the SCN during normal aging (Hofman and Swaab 2006). Having said this, there is evidence for alterations in distinct populations of neuropeptidergic neurons in the SCN: cell numbers expressing arginine vasopressin (AVP) do not show diurnal rhythms in older subjects compared to the marked rhythms observed in younger subjects (Hofman and Swaab 1994). Given a recently demonstrated role for AVP in maintaining circadian pacemaker resilience in the SCN (Yamaguchi et al. 2013), it is possible that alterations in SCN AVP production in part underpin the altered circadian resetting observed in older people and animals. Another key SCN neuropeptide, vasoactive intestinal polypeptide (VIP), also shows age-related changes. In males, aging is associated with a decrease in VIP expression. VIP appears to play a key role in the SCN neuronal network (Vosko et al. 2007) and so alterations in VIP expression could be a key contributor to circadian dysfunction in older age.

SCN expression of the MT1 melatonin receptor is also diminished in healthy aging in the human SCN, indicating that melatoninergic feedback to the SCN may be weakened in aging (Wu et al. 2007). These findings are in agreement with results from other similar studies that show that the 
SCN of aged rodents is less responsive to melatonin (Von Gall and Weaver 2008). Aside from decreased SCN sensitivity to melatonin, there is a considerable body of evidence that suggests melatonin secretion by the pineal gland is compromised by advancing age (Touitou 2001). In the elderly there is on average a $50 \%$ decline in nocturnal melatonin levels, although there are high levels of interindividual variation (Touitou 2001). Increased wakening after sleep onset, and concomitant increases in nocturnal light exposure, could possibly explain such suppression, especially given the recent suggestion that the human melatoninergic system is more sensitive to suppression by light than previously thought (Vartanian et al. 2015). A recent cohort study of melatonin in an elderly population has indicated that decreased 6-sulftoxymelatonin (a metabolite of melatonin) was associated with declined cognition and lower mood, and that these associations were independent of each other (Obayashi et al. 2015a). Other studies from the same cohort have indicated that higher melatonin secretion is associated with decreased white blood cell and platelet counts and with decreased arterial stiffness (Obayashi et al. 2014, 2015b). These results indicate that higher levels of melatonin secretion may be protective for numerous physiological systems in aging. Given that melatonin may exert anti-oxidant (Reiter et al. 2014) and anti-inflammatory actions (Hardeland et al. 2015), preserved functioning of the melatoninergic system into older age may produce multiple physiological benefits. Further, given the sleep-promoting properties of melatonin (Zhdanova 2005), there is the possibility that aging is associated with a vicious cycle. In such a cycle, weakened SCN circadian output leads to diminished amplitude of the sleep/wake cycle, more nocturnal awakening and more nocturnal light exposure; this in turn decreases nocturnal melatonin, lessens the feedback from melatonin back to the SCN and thus propagates weakened SCN output. This in turn would lead to more fragmented sleep, more sleep debt and the consequences associated with that (such as alterations in inflammatory mediators; Frey et al. 2007) against a background in which some of the protection of melatonin is lost due to age-related declines in its secretion and/or diminished responsively of target tissues. Recently it was suggested that the integrity of the cellular genome and metabolic function can be influenced by light at night and associated suppression of circadian melatonin production (Belancio et al. 2015).

An optimal regime for the use of exogenous melatonin, or melatoninergic agonists, to counter such effects in old age has yet to be formulated and thoroughly investigated (Vural et al. 2014).

Normal healthy aging is associated with low-grade chronic neuroinflammation ("inflammaging"; Baylis et al. 2013) and alterations of inflammatory processes in the hypothalamus have recently been shown to induce remarkable senescence-resistant phenotypes (Zhang et al. 2013a). Neuroinflammation within the aged SCN may therefore play a role in aging-related circadian dysfunction. SCN from older rodents has been shown to demonstrate elevated levels of microglial and astrocytic activation (Deng et al. 2010). Further aging has been associated with changes in SCN cytokine and cytokine receptor levels (Beynon and Coogan 2010; Beynon et al. 2009). Given that proinflammatory mediators such as tumor necrosis factor a $(\mathrm{TNF}-\alpha)$ and interferon-g (IFN- $\gamma$ ) can alter SCN neuronal function (Kwak et al. 2008; Nygård et al. 2009) and can alter circadian phase (Duhart et al. 2013; Paladino et al. 2014), there may be a role for age-related neuroinflammation in age-associated clock dysfunction. The induction of chronic neuroinflammation that persists following sepsis is also associated with altered circadian functioning, some facets of which (e.g. altered phase resetting) appear to resemble those reported in aged animal models (O'Callaghan et al. 2012). Further evidence for such a mechanism comes from drosophila models of Alzheimer's disease, wherein there are significant impacts on circadian rhythms in behavior, even though central clock neurons are spared (Long et al. 2014). These findings suggest that in these models a synaptic pathology, possibly associated with increased inflammation, is important in mediating the impairment of circadian rhythms in behavioral output, rather than behavioral impairment being a function of clock neuron dysfunction.

Given that aging is not associated with marked neuronal loss or other neuropathology in the SCN, it is important to note that several studies indicate that aging is associated with substantial alterations in SCN neurophysiology. SCN neurons normally show rhythms in their electrophysiological discharge rates in a neurochemical phenotype-dependent manner (Belle et al. 2009). The pattern of firing appears to be important physiological outputs of the SCN, and in the aged SCN there is a blunting of this rhythmic output (Farajnia et al. 2012; Nakamura et al. 2011; Watanabe et al. 1995). These changes in SCN output may be reflective of changes in the inter-neuronal coupling of the SCN network, a hypothesis that would be in keeping with the above-mentioned changes in neuropeptides in the aged SCN. Further, there have been descriptions of age-related changes in the GABAergic SCN (Palomba et al. 2008) as well as changes in responsiveness to glutamate, histamine and GABAergic stimulation (Biello 2009). The overall finding appears to be that the amplitude of SCN output decreases with age, perhaps through weakening of the SCN network and intraoscillator coupling (Farajnia et al. 2014); such an effect is consistent with the behavioral findings of dampened rhythm amplitudes in older age. 


\section{Clock genes and aging}

The discovery of the molecular clocks that control cell activity has expanded our understanding of physiology and behavior. However, the rhythmic mechanisms by which transcriptional signals can coordinate behavioral and physiological processes are not yet fully elucidated (Cho et al. 2012). The circadian clock generates the circadian rhythm and involves a panel of clock genes whose basic properties are conserved from flies to humans (Hardin, 2011). In most mammals, nearly all the cells and organs exhibit circadian modulation of gene expression (Dibner et al. 2010). However, the mechanisms underlying agerelated decay of the circadian system are still not well understood. The circadian rhythm is driven by a molecular clock involving a transcriptional negative-feedback loop. The canonical genes involved in the molecular system of the mammalian circadian clock include the Circadian Locomotor Output Cycles Kaput gene (clock), the Brain and Muscle ARNT-like protein 1 encoding gene (bmall), Period genes (perl, per2 and per3), Cryptochrome (cryl and cry2), and rev-erb- $\alpha$ (Nagoshi et al. 2010; Parish 2013; Rakshit and Giebultowicz 2013). The basic intrinsic mechanisms involve BMAL1 protein forming a heterodimeric complex with CLOCK (or NPAS2), which in turn drives the transcription of the per and cry genes and consequently increases PER and CRY protein levels. PER and CRY proteins are released from the nucleus into the cytoplasm where they form PER/CRY heterodimers. When the PER/CRY heterodimer concentration reaches the critical level they move back into the nucleus and acts as negative regulators of BMAL1-CLOCK/NPAS2 heterodimer, thereby inhibiting its own protein synthesis (PER/ CRY inhibitory feedback loop) (Dibner et al. 2010). Another two proteins have been described to modulate bmall gene expression. These proteins are represented by nuclear receptor subfamily 1 group D member 1 ( $n r l d l$, also known as rev-erb $\alpha$ ) and ROR-related orphan receptor 1 (rorl). Expression of rev-erb $\alpha$ and ror is driven by the CLOCK:BMAL1 complex, and feeds back onto bmall expression, adding a second feedback loop to the system. The clock gene cycle ultimately influences cellular physiology by regulating rhythmic expression of clock-controlled genes, in a tissue specific manner (Panda et al. 2002). Recent analysis has revealed that circadian control of the transcriptional landscape is surprisingly widespread and highly complex, and that non-transcriptional processes also play key roles in generating rhythmic molecular output (Koike et al. 2012).

A number of studies have examined the effects of aging on clock gene expression in various tissues. Middle age in mice was reported to be associated with alterations in the amplitude and/or phase of expression of the CLOCK and BMAL1 proteins in the SCN, hippocampus, amygdala and the paraventricular, arcuate and dorsomedial nuclei of the hypothalamus (Wyse and Coogan, 2010). Similar findings are reported for expression of mRNA for bmall and per 2 in non-SCN brain regions in older hamsters (Duncan et al. 2013). Further analysis of rhythmic clock gene expression patterns during aging shows that the SCN shows changes in rev-erb $a, d e c l$ and the clock-controlled gene $d b p$, and that heart and liver clocks also show significant changes in rhythmic clock gene expression (Bonaconsa et al. 2014). Aging does not seem to be associated with catastrophic loss of molecular rhythmicity in the SCN, as aged mice show a dampened rhythm of per 2 but an unaltered rhythm of perl (Weinert et al. 2001). Further, perl rhythms are not altered in the aged rat and hamster SCN (Asai et al. 2001; Kolker et al. 2003). The use of circadian clock gene reporter systems has further elucidated the impact of aging on molecular rhythms. Perl:luc rats show modest age-related changes in SCN rhythms, while peripheral oscillators show more profound changes in perl expression (Yamazaki et al. 2002). A further study using Perl:luc rats show that the rates of re-entrainment of peripheral oscillators to a phaseshift are altered with age, while the rate of SCN resetting is not altered (Davidson et al. 2008). Such a result may indicate that the mechanism through which phase information is conveyed from the central clock to peripheral clocks is altered with aging and such a mechanism may contribute to desynchronisation of constituent pacemakers of the circadian system; it is this desynchronisation that may underpin the deleterious effects of age-related circadian dysfunction.

There are obvious difficulties in the examination of clock gene expression cycles in human tissue, especially CNS tissue. Examination of post-mortem tissue has revealed that there are circadian rhythms of PER2, PER3 and BMAL1 in the cerebral cortices of the study participants who had a mean age of $\sim 85$ years, indicating that rhythmic expression persists in cortical areas into old age (Lim et al. 2013). Examination of clock gene expression patterns in leukocytes reveals that there are rhythms in PER1, 2, 3 present in older participants, although the phases of these rhythms are altered compared to younger subjects (Hida et al. 2009). Aged subjects also appear to show changes in circadian patterns in lymphocyte subpopulations, demonstrating that circadian effects of aging may translate into immunological changes (Mazzoccoli et al. 2011).

Via which mechanism might clock gene expression be modulated in aging? Recent studies have focused on the cross talk between the circadian and metabolic control systems to identify modulators that may be of importance in 
aging. One such mediator is SIRT1. SIRT1 impacts on the central circadian clock in the brain by activating the transcription of the two major circadian regulators, bmall and clock. SIRT1 action involves another two players, peroxisome proliferator-activated receptor gamma coactivator 1 -alpha (PGC-1 $\alpha$ ) that is encoded peroxisome proliferatoractivated receptor gamma coactivator 1 (ppargcl) gene and nicotinamide phosphoribosyltransferase (NAMPT) (Ramsey et al. 2009; Chang and Guarente 2013). SIRT1 and PGC-1 $\alpha$ form a regulatory complex that integrates the mammalian clock, energy metabolism, cellular stress and lipid metabolism (Liu et al. 2007; Wang and Lung 2012). PGC-1 $\alpha$ stimulates the expression of the clock genes, bmall and rev-erb- $\alpha$, through coactivation of the ROR family receptors. In aged, wild-type mice, SIRT1 level in the SCN is decreased concomitantly with levels of BMAL1 and PER2 (Chang and Guarente 2013). Further, older animals show altered free-running period, entrainment and phase resetting. Intriguingly, sirtl knockout results in a senescent-like phenotype on these circadian parameters, while sirtl over-expression results in an anti-aging phenotype in terms of circadian changes (Chang and Guarente 2013). SIRTs are also proposed to contribute to epigenetic changes that occur in the clock with aging (Orozco-Solis and Sassone-Corsi 2014). Aging has been shown to impact on clock gene methylation in various peripheral tissues (Zhang et al. 2013b). Another signaling pathway that may be involved in age-related epigenetic clock modifications is the mTOR cascade, as mTOR is associated with cellular senescence (Orozco-Solis and Sassone-Corsi 2014) and is also associated with clock function (Cao et al. 2011, 2013); therefore it may play a role in linking the clock to aging (Khapre et al. 2014).

\section{Circadian rhythm and healthy aging}

There are a number of lines of evidence that suggest that proper circadian function is important in healthy aging. Firstly there is evidence based on the circadian resonance theory which hypothesizes that the environmental cycles that animals are exposed to should display periods that best match the period of the intrinsic circadian pacemaker for optimal physiological outcomes. This hypothesis is supported by evidence pertaining to the association between free-running period and longevity, with deviation of freerunning period (the length of the circadian cycle expressed in constant environmental conditions) away from $24 \mathrm{~h}$ being associated with shorter life spans in different rodent species and mouse strains (Wyse et al. 2010). Further support from this idea comes from experimental studies examining free-running periods of individual mice, which show that the free-running periods closer to $24 \mathrm{~h}$ are associated with greater longevity (Libert et al. 2012). Interestingly, the tau mutant hamster, which has a freerunning period of $\sim 20 \mathrm{~h}$, shows enhanced longevity compared to wild types when housed in constant dim red light (Oklejewicz and Daan 2002), while a previous study had indicated that heterozygous tau mutant animals (with a period of about $22 \mathrm{~h}$ ) housed under a 12:12 light:dark cycle showed reduced longevity (Hurd and Ralph 1998). Converse findings are reported for the long-lived MUPA mouse which displays circadian free-running periods of $24 \mathrm{~h}$ at both young and older ages, compared to the wild-type controls whose periods deviate from $24 \mathrm{~h}$ (Gutman et al. 2011). These findings may indicate that it is not the deviation of the period from $24 \mathrm{~h}$ per se that is important, rather the mismatch between the circadian period and the period of the imposed light/dark cycle. Other studies have shown that an abrupt phase-advance of the light dark cycle can induce remarkable mortality in aged rats and mice (Davidson et al. 2006, 2008), indicating that as the circadian system ages it becomes very sensitive to acute large perturbations.

There is also evidence that clock genes may play important roles in healthy aging aside from their roles in dictating functional circadian rhythms. Mice deficient in clock genes show impaired average and maximum life spans: for example, the clock knockout mouse shows a $15 \%$ reduction in average life span (Dubrovsky et al. 2010). The clock gene bmall is the only obligate mammalian clock gene for behavioral rhythmicity, with bmall knockout animals showing no circadian rhythms under free-running conditions (Bunger et al. 2000). These animals also show a remarkably severe accelerated aging phenotype (Kondratov et al. 2006). This phenotype includes cataract development, sarcopenia, leanness and very premature mortality (an average life span of only 37 weeks; Kondratov et al. 2006). Bmall has been shown to be involved in redox homeostasis, and its knockout results in profound astrogliosis in the brain and neurodegeneration, independent of the loss of circadian rhythms in behavior (Musiek et al. 2013). Bmall also interacts with the NF- $\kappa \mathrm{B}$ signaling system, and it has been proposed that bmall knockout results in a chronic inflammatory state that contributes to the accelerated aging phenotype (Spengler et al. 2012).

\section{Circadian rhythms in age-related diseases}

Circadian rhythm and sleep disturbances are described as being prominent in a number of chronic, age-related conditions. These include Alzheimer's disease (Coogan et al. 2013), age-related cognitive decline and mild cognitive impairment (Cochrane et al. 2012; Ortiz-Tudela 
et al. 2014; Naismith et al. 2014), Parkinson's disease (Breen et al. 2014), rheumatoid arthritis (De Cata et al. 2014), type II diabetes mellitus (Rakshit et al. 2014) and cancer (Palesh et al. 2014). Further circadian rhythm disturbances are reported in a number of life-long psychiatric conditions such as schizophrenia (Wulff et al. 2012), bipolar disorder (Robillard et al. 2013) and adult attention deficit hyperactivity disorder (Baird et al. 2012). Age may also play an important role in linking circadian disruption to mood disorders, such that the nature of the circadian rhythms observed, for example, in young patients with major depression may differ markedly from those in older patients with major depression (Campos Costa et al. 2013). An interesting facet is that circadian and/or sleep disturbances may be prodromal signs of common illnesses of old age. This possibility was highlighted in a prospective cohort study which demonstrated that circadian rhythm changes in locomotion are significant predictors of subsequent dementia or mild cognitive impairment (Tranah et al. 2011). Such sub-clinical changes may represent novel diagnostic opportunities that allow for early intervention. In terms of delivering chronotherapeutic interventions to ameliorate circadian dysfunction, it is important to appreciate the nature of the dysfunction first. As healthy aging and, in a more exaggerated manner, neurodegenerative disorders are accompanied by marked dampening of circadian amplitude and rhythm fragmentation, chronotherapeutic interventions that involve strengthened zeitgebers may prove most effective. The use of brighter lights in nursing home day rooms has already been shown to be effective in slowing cognitive decline (Riemersa-van der Lek et al. 2008). Other interventions, such as scheduled exercise, may also prove effective and there is good evidence from preclinical models for this strategy (Leise et al. 2013; Power et al. 2010). For other conditions, such as mood disorders, the most notable circadian changes are those in phase and desynchronisation of output rhythms, and such changes suggest that the most fruitful approaches will involve chronotherapy that reset clock phase (Coogan and Thome 2011).

\section{Conclusion}

We have outlined evidence above that illustrates the fascinating, bidirectional relationship between aging and the circadian system. As the world population thankfully continues to live longer, understanding how the circadian system may be manipulated by environmental, behavioral and pharmacological interventions to increase health in old age and attenuate the development and severity of chronic illnesses becomes more important, and this in turn signals a pressing need for more research focussed on this important question.

Conflict of interest We have no conflict of interest to declare.

\section{References}

Arellanes-Licea E, Caldelas I, De Ita-Pérez D, Díaz-Muñoz M (2014) The circadian timing system: a recent addition in the physiological mechanisms underlying pathological and aging processes. Aging Dis. 5(6):406-418. doi:10.14336/AD.2014. 0500406

Asai M, Yoshinobu Y, Kaneko S, Mori A, Nikaido T, Moriya T, Akiyama M, Shibata S (2001) Circadian profile of Per gene mRNA expression in the suprachiasmatic nucleus, paraventricular nucleus, and pineal body of aged rats. J Neurosci Res 66(6):1133-1139

Baird AL, Coogan AN, Siddiqui A, Donev RM, Thome J (2012) Adult attention-deficit hyperactivity disorder is associated with alterations in circadian rhythms at the behavioural, endocrine and molecular levels. Mol Psychiatry 17(10):988-995. doi:10. 1038/mp.2011.149

Baylis D, Bartlett DB, Patel HP, Roberts HC (2013) Understanding how we age: insights into inflammaging. Longev Healthspan 2(1):8. doi:10.1186/2046-2395-2-8

Belancio VP, Blask DE, Deininger P, Hill SM, Jazwinski SM (2015) The aging clock and circadian control of metabolism and genome stability. Front Genet. 14(5):455. doi:10.3389/fgene. 2014.00455

Belle MD, Diekman CO, Forger DB, Piggins HD (2009) Daily electrical silencing in the mammalian circadian clock. Science 326(5950):281-284. doi:10.1126/science.1169657

Beynon AL, Coogan AN (2010) Diurnal, age, and immune regulation of interleukin-1 $\beta$ and interleukin- 1 type 1 receptor in the mouse suprachiasmatic nucleus. Chronobiol Int 27(8):1546-1563. doi: $10.3109 / 07420528.2010 .501927$

Beynon AL, Thome J, Coogan AN (2009) Age and time of day influences on the expression of transforming growth factor-beta and phosphorylated SMAD3 in the mouse suprachiasmatic and paraventricular nuclei. NeuroImmunoModulation 16(6): 392-399. doi: $10.1159 / 000228914$

Biello SM (2009) Circadian clock resetting in the mouse changes with age. Age (Dordr) 31(4):293-303. doi:10.1007/s11357-009-9102-7

Bonaconsa M, Malpeli G, Montaruli A, Carandente F, Grassi-Zucconi G, Bentivoglio M (2014) Differential modulation of clock gene expression in the suprachiasmatic nucleus, liver and heart of aged mice. Exp Gerontol 55:70-79. doi:10.1016/j.exger.2014.03. 011

Breen DP, Vuono R, Nawarathna U, Fisher K, Shneerson JM, Reddy AB, Barker RA (2014) Sleep and circadian rhythm regulation in early Parkinson disease. JAMA Neurol 71(5):589-595. doi:10. 1001/jamaneurol.2014.65

Bunger MK, Wilsbacher LD, Moran SM, Clendenin C, Radcliffe LA, Hogenesch JB, Simon MC, Takahashi JS, Bradfield CA (2000) Mop3 is an essential component of the master circadian pacemaker in mammals. Cell 103(7):1009-1017

Campos Costa I, Nogueira Carvalho H, Fernandes L (2013) Aging, circadian rhythms and depressive disorders: a review. Am J Neurodegener Dis 2(4):228-246

Cao R, Anderson FE, Jung YJ, Dziema H, Obrietan K (2011) Circadian regulation of mammalian target of rapamycin signaling in the mouse suprachiasmatic nucleus. Neuroscience 181:79-88. doi:10.1016/j.neuroscience.2011.03.005 
Cao R, Robinson B, Xu H, Gkogkas C, Khoutorsky A, Alain T, Yanagiya A, Nevarko T, Liu AC, Amir S, Sonenberg N (2013) Translational control of entrainment and synchrony of the suprachiasmatic circadian clock by mTOR/4E-BP1 signaling. Neuron 79(4):712-724. doi:10.1016/j.neuron.2013.06.026

Chang HC, Guarente L (2013) SIRT1 mediates central circadian control in the SCN by a mechanism that decays with aging. Cell 153(7):1448-1460. doi:10.1016/j.cell.2013.05.027

Cho H, Zhao X, Hatori M, Yu RT, Barish GD, Lam MT, Chong LW, DiTacchio L, Atkins AR, Glass CK, Liddle C, Auwerx J, Downes M, Panda S, Evans RM (2012) Regulation of circadian behaviour and metabolism by REV-ERB- $\alpha$ and REV-ERB- $\beta$. Nature 485(7396):123-127. doi:10.1038/nature11048

Cochrane A, Robertson IH, Coogan AN (2012) Association between circadian rhythms, sleep and cognitive impairment in healthy older adults: an actigraphic study. J Neural Transm 119(10):1233-1239. doi:10.1007/s00702-012-0802-2

Coogan AN, Thome J (2011) Chronotherapeutics and psychiatry: setting the clock to relieve the symptoms. World J Biol Psychiatry 12(Suppl 1):40-43. doi:10.3109/15622975.2011. 598389

Coogan AN, Schutová B, Husung S, Furczyk K, Baune BT, Kropp P, Häßler F, Thome J (2013) The circadian system in Alzheimer's disease: disturbances, mechanisms, and opportunities. Biol Psychiatry 74(5):333-339. doi:10.1016/j.biopsych.2012.11.021

Czeisler CA, Duffy JF, Shanahan TL, Brown EN, Mitchell JF, Rimmer DW, Ronda JM, Silva EJ, Allan JS, Emens JS, Dijk DJ, Kronauer RE (1999) Stability, precision, and near-24-hour period of the human circadian pacemaker. Science 284(5423):2177-2181

Davidson AJ, Sellix MT, Daniel J, Yamazaki S, Menaker M, Block GD (2006) Chronic jet-lag increases mortality in aged mice. Curr Biol 16(21):R914-R916. doi:10.1016/j.cub.2006.09.058

Davidson AJ, Yamazaki S, Arble DM, Menaker M, Block GD (2008) Resetting of central and peripheral circadian oscillators in aged rats. Neurobiol Aging 29(3):471-477. doi:10.1016/j.neurobiola ging.2006.10.018

De Cata A, D'Agruma L, Tarquini R, Mazzoccoli G (2014) Rheumatoid arthritis and the biological clock. Expert Rev Clin Immunol 10(5):687-695. doi:10.1586/1744666X.2014.899904

Deng XH, Bertini G, Palomba M, Xu YZ, Bonaconsa M, Nygård M, Bentivoglio M (2010) Glial transcripts and immune-challenged glia in the suprachiasmatic nucleus of young and aged mice. Chronobiol Int 27(4):742-767. doi:10.3109/0742052100 3681498

Dibner C, Schibler U, Albrecht U (2010) The mammalian circadian timing system: organization and coordination of central and peripheral clocks. Annu Rev Physiol 72:517-549. doi:10.1146/ annurev-physiol-021909-135821

Dubrovsky YV, Samsa WE, Kondratov RV (2010) Deficiency of circadian protein CLOCK reduces lifespan and increases agerelated cataract development in mice. Aging (Albany NY) 2(12):936-944

Duffy JF, Czeisler CA (2002) Age-related change in the relationship between circadian period, circadian phase, and diurnal preference in humans. Neurosci Lett 318(3):117-120

Duhart JM, Leone MJ, Paladino N, Evans JA, Castanon-Cervantes O, Davidson AJ, Golombek DA (2013) Suprachiasmatic astrocytes modulate the circadian clock in response to TNF- $\alpha$. J Immunol 191(9):4656-4664. doi:10.4049/jimmunol.1300450

Duncan MJ, Prochot JR, Cook DH, Tyler Smith J, Franklin KM (2013) Influence of aging on Bmal1 and Per2 expression in extra-SCN oscillators in hamster brain. Brain Res 1491:44-53. doi:10.1016/j.brainres.2012.11.008

Farajnia S, Michel S, Deboer T, van derLeest HT, Houben T, Rohling JH, Ramkisoensing A, Yasenkov R, Meijer JH (2012) Evidence for neuronal desynchrony in the aged suprachiasmatic nucleus clock. J Neurosci 32(17):5891-5899. doi:10.1523/JNEUROSCI. 0469-12.2012

Farajnia S, Deboer T, Rohling JH, Meijer JH, Michel S (2014) Aging of the suprachiasmatic clock. Neuroscientist 20(1):44-55. doi:10.1177/1073858413498936

Ferrucci L, Giallauria F, Guralnik JM (2008) Epidemiology of aging. Radiol Clin North Am 46(4):643-665. doi:10.1016/j.rcl.2008.07. 005

Franken P (2013) A role for clock genes in sleep homeostasis. Curr Opin Neurobiol 23(5):864-872. doi:10.1016/j.conb.2013.05.002

Frey DJ, Fleshner M, Wright KP Jr (2007) The effects of 40 hours of total sleep deprivation on inflammatory markers in healthy young adults. Brain Behav Immun 21(8):1050-1057

Guilding C, Piggins HD (2007) Challenging the omnipotence of the suprachiasmatic timekeeper: are circadian oscillators present throughout the mammalian brain? Eur J Neurosci 25(11):3195-3216. doi:10.1111/j.1460-9568.2007.05581

Gutman R, Genzer Y, Chapnik N, Miskin R, Froy O (2011) Longlived mice exhibit $24 \mathrm{~h}$ locomotor circadian rhythms at young and old age. Exp Gerontol 46(7):606-609. doi:10.1016/j.exger. 2011.02.015

Hardeland R, Cardinali DP, Brown GM, Pandi-Perumal SR (2015) Melatonin and brain inflammaging. Prog Neurobiol 127-128C:46-63

Hardin PE (2011) Molecular genetic analysis of circadian timekeeping in Drosophila. Adv Genet 74:141-173. doi:10.1016/B978-012-387690-4.00005-2

Hida A, Kusanagi H, Satoh K, Kato T, Matsumoto Y, Echizenya M, Shimizu T, Higuchi S, Mishima K (2009) Expression profiles of PERIOD1, 2, and 3 in peripheral blood mononuclear cells from older subjects. Life Sci 84(1-2):33-37. doi:10.1016/j.lfs.2008. 10.012

Hofman MA, Swaab DF (1994) Alterations in circadian rhythmicity of the vasopressin-producing neurons of the human suprachiasmatic nucleus (SCN) with aging. Brain Res 651(1-2):134-142

Hofman MA, Swaab DF (2006) Living by the clock: the circadian pacemaker in older people. Ageing Res Rev 5(1):33-51. doi:10. 1016/j.arr.2005.07.001

Hurd MW, Ralph MR (1998) The significance of circadian organization for longevity in the golden hamster. J Biol Rhythms 13(5):430-436

Khapre RV, Kondratova AA, Patel S, Dubrovsky Y, Wrobel M, Antoch MP, Kondratov RV (2014) BMAL1-dependent regulation of the mTOR signaling pathway delays aging. Aging (Albany NY) 6(1):48-57

Koike N, Yoo SH, Huang HC, Kumar V, Lee C, Kim TK, Takahashi JS (2012) Transcriptional architecture and chromatin landscape of the core circadian clock in mammals. Science 338(6105):349-354. doi:10.1126/science.1226339

Kolker DE, Fukuyama H, Huang DS, Takahashi JS, Horton TH, Turek FW (2003) Aging alters circadian and light-induced expression of clock genes in golden hamsters. J Biol Rhythms 18(2):159-169

Kondratov RV, Kondratova AA, Gorbacheva VY, Vykhovanets OV, Antoch MP (2006) Early aging and age-related pathologies in mice deficient in BMAL1, the core componentof the circadian clock. Genes Dev 20(14):1868-1873. doi:10.1101/gad.1432206

Kwak Y, Lundkvist GB, Brask J, Davidson A, Menaker M, Kristensson K, Block GD (2008) Interferon-gamma alters electrical activity and clock gene expression in suprachiasmatic nucleus neurons. J Biol Rhythms 23(2):150-159. doi:10.1177/ 0748730407313355

Leise TL, Harrington ME, Molyneux PC, Song I, Queenan H, Zimmerman E, Lall GS, Biello SM (2013) Voluntary exercise can strengthen the circadian system in aged mice. Age (Dordr) 35(6):2137-2152. doi:10.1007/s11357-012-9502-y 
Libert S, Bonkowski MS, Pointer K, Pletcher SD, Guarente L (2012) Deviation of innate circadian period from $24 \mathrm{~h}$ reduces longevity in mice. Aging Cell 11(5):794-800. doi:10.1111/j.1474-9726. 2012.00846.x

Lim AS, Myers AJ, Yu L, Buchman AS, Duffy JF, De Jager PL, Bennett DA (2013) Sex difference in daily rhythms of clock gene expression in the aged human cerebral cortex. J Biol Rhythms 28(2):117-129. doi:10.1177/0748730413478552

Liu C, Li S, Liu T, Borjigin J, Lin JD (2007) Transcriptional coactivator PGC-1alpha integrates the mammalian clock and energy metabolism. Nature 447:477-481

Long DM, Blake MR, Dutta S, Holbrook SD, Kotwica-Rolinska J, Kretzschmar D, Giebultowicz JM (2014) Relationships between the Circadian system and Alzheimer's Disease-like symptoms in Drosophila. PLoS One 9(8):e106068. doi:10.1371/journal.pone. 0106068

Mazzoccoli G, Carughi S, Sperandeo M, Pazienza V, Giuliani F, Greco A (2011) Alteration of circadian rhythmicity of CD3+ CD4+ lymphocyte subpopulation in healthy aging. J Biol Regul Homeost Agents 25(3):405-416

Moore RY (2007) Suprachiasmatic nucleus in sleep-wake regulation. Sleep Med Suppl 3:27-33

Musiek ES, Lim MM, Yang G, Bauer AQ, Qi L, Lee Y, Roh JH, Ortiz-Gonzalez X, Dearborn JT, Culver JP, Herzog ED, Hogenesch JB, Wozniak DF, Dikranian K, Giasson BI, Weaver DR, Holtzman DM, Fitzgerald GA (2013) Circadian clock proteins regulate neuronal redox homeostasis and neurodegeneration. J Clin Invest 123(12):5389-5400. doi:10.1172/JCI70317

Nagoshi E, Sugino K, Kula E, Okazaki E, Tachibana T, Nelson S (2010) Dissecting differential gene expression within the circadian neuronal circuit of Drosophila. Nat Neurosci 13:60-68. doi:10.1038/nn.2451

Naismith SL, Hickie IB, Terpening Z, Rajaratnam SM, Rajaratnam SW, Hodges JR, Bolitho S, Rogers NL, Lewis SJ (2014) Circadian misalignment and sleep disruption in mild cognitive impairment. J Alzheimers Dis 38(4):857-866. doi:10.3233/JAD131217

Nakamura TJ, Nakamura W, Yamazaki S, Kudo T, Cutler T, Colwell CS, Block GD (2011) Age-related decline in circadian output. J Neurosci 31(28):10201-10205. doi:10.1523/JNEUROSCI. 0451-11.2011

Nygård M, Lundkvist GB, Hill RH, Kristensson K (2009) Rapid nitric oxide-dependent effects of tumor necrosis factor-alpha on suprachiasmatic nuclei neuronal activity. NeuroReport 20(2): 213-217. doi:10.1097/WNR.0b013e32831f1ca2

Obayashi K, Saeki K, Kurumatani N (2014) Association between urinary 6-sulfatoxymelatonin excretion and arterial stiffness in the general elderly population: the HEIJO-KYO cohort. J Clin Endocrinol Metab 99(9):3233-3239

Obayashi K, Saeki K, Iwamoto J, Tone N, Tanaka K, Kataoka H, Morikawa M (2015a) Kurumatani N (2015a). Physiological levels of melatonin relate to cognitive function and depressive symptoms, The HEIJO-KYO Cohort. J Clin Endocrinol Metab

Obayashi K, Saeki K, Kurumatani N (2015b) Higher melatonin secretion is associated with lower leukocyte and platelet counts in the general elderly population: the HEIJO-KYO cohort. J Pineal Res 58(2):227-233

O'Callaghan EK, Anderson ST, Moynagh PN, Coogan AN (2012) Long-lasting effects of sepsis on circadian rhythms in the mouse. PLoS One 7(10):e47087. doi:10.1371/journal.pone.0047087

Oklejewicz M, Daan S (2002) Enhanced longevity in tau mutant Syrian hamsters. Mesocricetus auratus. J Biol Rhythms 17(3):210-216

Oosterman JM, van Someren EJ, Vogels RL, Van Harten B, Scherder EJ (2009) Fragmentation of the rest-activity rhythm correlates with age-related cognitive deficits. J Sleep Res 18(1):129-135. doi:10.1111/j.1365-2869.2008.00704.x

Orozco-Solis R, Sassone-Corsi P (2014) Circadian clock: linking epigenetics to aging. Curr Opin Genet Dev 26C:66-72. doi:10. 1016/j.gde.2014.06.003

Ortiz-Tudela E, Martinez-Nicolas A, Díaz-Mardomingo C, GarcíaHerranz S, Pereda-Pérez I, Valencia A, Peraita H, Venero C, Madrid JA, Rol MA (2014) The characterization of biological rhythms in mild cognitive impairment. Biomed Res Int 2014:524971. doi:10.1155/2014/524971

Paladino N, Mul Fedele ML, Duhart JM, Marpegan L, Golombek DA (2014) Modulation of mammalian circadian rhythms by tumor necrosis factor- $\alpha$. Chronobiol Int 31(5):668-679. doi:10.3109/ 07420528.2014 .886588

Palesh O, Aldridge-Gerry A, Zeitzer JM, Koopman C, Neri E, GieseDavis J, Jo B, Kraemer H, Nouriani B, Spiegel D (2014) Actigraphy-measured sleep disruption as a predictor of survival among women with advanced breast cancer. Sleep 37(5):837-842. doi:10.5665/sleep.3642

Palomba M, Nygård M, Florenzano F, Bertini G, Kristensson K, Bentivoglio M (2008) Decline of the presynaptic network, including GABAergic terminals, in the aging suprachiasmatic nucleus of the mouse. J Biol Rhythms 23(3):220-231. doi:10. 1177/0748730408316998

Panda S, Antoch MP, Miller BH, Su AI, Schook AB, Straume M, Schultz PG, Kay SA, Takahashi JS, Hogenesch JB (2002) Coordinated transcription of key pathways in the mouse by the circadian clock. Cell 109(3):307-320

Parish JM (2013) Genetic and immunologic aspects of sleep and sleep disorders. Chest 143(5):1489-1499. doi:10.1378/chest.12-1219

Power A, Hughes AT, Samuels RE, Piggins HD (2010) Rhythmpromoting actions of exercise in mice with deficient neuropeptide signaling. J Biol Rhythms 25(4):235-246. doi:10.1177/ 0748730410374446

Rakshit K, Giebultowicz JM (2013) Cryptochrome restores dampened circadian rhythms and promotes healthspan in aging Drosophila. Aging Cell 12:752-762. doi:10.1111/acel.12100

Rakshit K, Thomas AP, Matveyenko AV (2014) Does disruption of circadian rhythms contribute to beta-cell failure in type 2 diabetes? Curr Diab Rep 14(4):474. doi:10.1007/s11892-0140474-4

Ramsey KM, Yoshino J, Brace CS, Abrassart D, Kobayashi Y, Marcheva B, Hong HK, Chong JL, Buhr ED, Lee C, Takahashi JS, Imai S, Bass J (2009) Circadian clock feedback cycle through NAMPT-mediated NAD+ biosynthesis. Science 324(5927): 651-654. doi:10.1126/science.1171641

Reiter RJ, Tan DX, Galano A (2014) Melatonin: exceeding expectations. Physiol (Bethesda) 29(5):325-333

Riemersa-van der Lek RF, Swaab DF, Twisk J, Hol EM, Hoogendijk WJ, Van Someren EJ (2008) Effect of bright light and melatonin on cognitive and noncognitive function in elderly residents of group care facilities: a randomized controlled trial. JAMA 299(22):2642-2655. doi:10.1001/jama.299.22.2642

Robillard R, Naismith SL, Hickie IB (2013) Recent advances in sleepwake cycle and biological rhythms in bipolar disorder. Curr Psychiatry Rep 15(10):402. doi:10.1007/s11920-013-0402-3

Roenneberg T, Wirz-Justice A, Merrow M (2003) Life between clocks: daily temporal patterns of human chronotypes. J Biol Rhythms 18(1):80-90

Saper CB, Lu J, Chou TC, Gooley J (2005) The hypothalamic integrator for circadian rhythms. Trends Neurosci 28(3):152157. doi:10.1016/j.tins.2004.12.009

Smolensky MH, Portaluppi F, Manfredini R, Hermida RC, Tiseo R, Sackett-Lundeen LL, L Haus E (2015) Diurnal and twenty-four hour patterning of human diseases: acute and chronic common 
and uncommon medical conditions. Sleep Med Rev 21:3-11. doi:10.1016/j.smrv.2014.07.001

Spengler ML, Kuropatwinski KK, Comas M, Gasparian AV, Fedtsova N, Gleiberman AS, Gitlin II, Artemicheva NM, Deluca KA, Gudkov AV, Antoch MP (2012) Core circadian protein CLOCK is a positive regulator of NF- $\mathrm{KB}$-mediated transcription. Proc Natl Acad Sci USA 109(37):E2457-E2465. doi:10.1073/pnas. 1206274109

Stiller JW, Postolache TT (2005) Sleep-wake and other biological rhythms: functional neuroanatomy. Clin Sports Med 24(2): 205-235

Touitou Y (2001) Human aging and melatonin. Clinical relevance. Exp Gerontol 36(7):1083-1100

Tranah GJ, Blackwell T, Stone KL, Ancoli-Israel S, Paudel ML, Ensrud KE, Cauley JA, Redline S, Hillier TA, Cummings SR, Yaffe K, Group SR (2011) Circadian activity rhythms and risk of incident dementia and mild cognitive impairment in older women. Ann Neurol 70(5):722-732. doi:10.1002/ana.22468

Vartanian GV, Li BY, Chervenak AP, Walch OJ, Pack W, AlaLaurila P, Wong KY (2015) Melatonin suppression by light in humans is more sensitive than previously reported. J Biol Rhythms 30(4):351-354. doi:10.1177/0748730415585413

von Gall C, Weaver DR (2008) Loss of responsiveness to melatonin in the aging mouse suprachiasmatic nucleus. Neurobiol Aging 29(3):464-470. doi:10.1016/j.neurobiolaging.2006.10.015

Vosko AM, Schroeder A, Loh DH, Colwell CS (2007) Vasoactive intestinal peptide and the mammalian circadian system. Gen Comp Endocrinol 152(2-3):165-175. doi:10.1016/j.ygcen.2007. 04.018

Vural EM, van Munster BC, de Rooij SE (2014) Optimal dosages for melatonin supplementation therapy in older adults: a systematic review of current literature. Drugs Aging 31(6):441-451

Wang CC, Lung FW (2012) The role of PGC-1 and Apoe4 in insomnia. Psychiatr Genet 22:82-87

Watanabe A, Shibata S, Watanabe S (1995) Circadian rhythm of spontaneous neuronal activity in the suprachiasmatic nucleus of old hamster in vitro. Brain Res 695(2):237-239

Weinert H, Weinert D, Schurov I, Maywood ES, Hastings MH (2001) Impaired expression of the mPer2 circadian clock gene in the suprachiasmatic nuclei of aging mice. Chronobiol Int 18(3):559-565
Wu YH, Zhou JN, Van Heerikhuize J, Jockers R, Swaab DF (2007) Decreased MT1 melatonin receptor expression in the suprachiasmatic nucleus in aging and Alzheimer's disease. Neurobiol Aging 28(8):1239-1247. doi:10.1016/j.neurobiolaging.2006.06. 002

Wulff K, Dijk DJ, Middleton B, Foster RG, Joyce EM (2012) Sleep and circadian rhythm disruption in schizophrenia. Br J Psychiatry 200(4):308-316. doi:10.1192/bjp.bp.111.096321

Wyse CA, Coogan AN (2010) Impact of aging on diurnal expression patterns of CLOCK and BMAL1 in the mouse brain. Brain Res 1337:21-31. doi:10.1016/j.brainres.2010.03.113

Wyse CA, Coogan AN, Selman C, Hazlerigg DG, Speakman JR (2010) Association between mammalian lifespan and circadian free-running period: the circadian resonance hypothesis revisited. Biol Lett 6(5):696-698. doi:10.1098/rsbl.2010.0152

Yamaguchi Y, Suzuki T, Mizoro Y, Kori H, Okada K, Chen Y, Fustin JM, Yamazaki F, Mizuguchi N, Zhang J, Dong X, Tsujimoto G, Okuno Y, Doi M, Okamura H (2013) Mice genetically deficient in vasopressin $\mathrm{V} 1 \mathrm{a}$ and $\mathrm{V} 1 \mathrm{~b}$ receptors are resistant to jet lag. Science 342(6154):85-90. doi:10.1126/science.1238599

Yamazaki S, Straume M, Tei H, Sakaki Y, Menaker M, Block GD (2002) Effects of aging on central and peripheral mammalian clocks. Proc Natl Acad Sci USA 99(16):10801-10806. doi:10. 1073/pnas.152318499

Yoon IY, Kripke DF, Youngstedt SD, Elliott JA (2003) Actigraphy suggests age-related differences in napping and nocturnal sleep, J Sleep Res 12(2):87-93

Zeman A, Reading P (2005) The science of sleep. Clin Med 5:97-101

Zhang G, Li J, Purkayastha S, Tang Y, Zhang H, Yin Y, Li B, Liu G, Cai D (2013a) Hypothalamic programming of systemic ageing involving IKK- $\beta, \quad \mathrm{NF}-\kappa \mathrm{B}$ and GnRH. Nature 497(7448): 211-216. doi:10.1038/nature12143

Zhang L, Lin QL, Lu L, Yang CC, Li YL, Sun FL, Wang DH, Cai YN, Li L (2013b) Tissue-specific modification of clock methylation in aging mice. Eur Rev Med Pharmacol Sci 17(14): 1874-1880

Zhdanova IV (2005) Melatonin as a hypnotic: pro. Sleep Med Rev 9(1):51-65 